\title{
Expondo a si mesmas: homenagem às professoras do departamento de Filosofia da USP e o processo de escuta
}

\author{
Carla Milani Damião
}

Resumo: Este artigo visa tratar do relato e da memória de onze professoras que compõem ou compuseram o corpo docente do departamento de Filosofia da Universidade de São Paulo. Testemunhos de diferentes intensidades apresentados no II Encontro do GT de Filosofia e Gênero da ANPOF, realizado em setembro de 2019 no Departamento de Filosofia (FFLCH) da USP. Buscase, com a mesma atenção, a fundamentação de teorias feministas sobre a narrativa e a escuta de mulheres, tendo por esteio uma nova compreensão de subjetividade que pressupõe a crítica à tradição do pensamento filosófico e à construção metafísica da subjetividade. Com base na ideia de "eu relacional", a crítica não homogênea de feministas torna possível uma compreensão de relatos variados, testemunhos de opressão revelados e de discriminações, revelados em narrativas.

Palavras-chave: Subjetividade - Narrativa - Testemunho - Memória - Mulheres

\section{Exposing themselves: homage to the professors of the USP department of philosophy and the listening process}

\begin{abstract}
This article aims to deal with narratives and memory of eleven women professors, who were or are part of the Philosophy Department at the University of São Paulo. They are testimonies of different intensities presented at the $2^{\circ}$ Meeting of the ANPOF Philosophy and Gender Research Group, held in September 2019 at the Philosophy Department (FFLCH) of USP. We seek, with the same consideration, to base feminist theories on women's narrative together with listening, concerning a new understanding of subjectivity that presupposes the criticism of the philosophical tradition of thought and the metaphysical construction of subjectivity. Based on the idea of "relational self", the inhomogeneous criticism of feminists makes it possible to understand varied accounts, revealed testimonies of oppression and discrimination in relevant in the narratives.
\end{abstract}

Keywords: Subjectivity - Narrative - Testimony - Memory - Women

1 Professora na Faculdade de Filosofia da Universidade Federal de Goiás (FAFIL-UFG). E-mail: cmdw16@ufg.br 


\section{Apresentação}

Esse artigo inicia tomando uma posição clara: a da escuta em relação a testemunhos que possuem camadas mais ou menos profundas. Uma escuta permeada pela leitura de um corpo teórico composto também em camadas ou, no jargão mais utilizado quando falamos em feminismos, em ondas. A tentação de intitular esse texto como "a nossa onda" foi superada em vista da necessidade de explicar que ondas foram essas, que altura alcançaram, onde foram tão gigantescas que chegaram a alterar ideias, valores, linguagens e comportamentos. No âmbito da filosofia que se faz nos departamentos de Filosofia no Brasil, parece existir mais uma espécie de ressaca marítima, uma onda que nunca se formou naturalmente, distanciada da costa, mas que bruscamente bateu para além dos limites da praia. A própria constituição de um Grupo de Trabalho na Associação Nacional de PósGraduação em Filosofia (ANPOF) que ousou discutir gênero, feminismo, raça e decolonialismo no contexto de discussões que envolvem pesquisa de pós-graduação em Filosofia no Brasil2 ${ }^{2}$ foi essa espécie de onda súbita que atingiu massivamente a promenade dos programas de pós-graduação em Filosofia, o passeio dos filósofos. Os colegas homens "tomaram um caldo" em plena passarela acadêmica ao perceberem que deveriam se dirigir às colegas e estudantes mulheres de maneira mais apropriada, cumprimentando a todas de forma a reconhecer sua diferença.

As professoras que nos antecederam viveram períodos que já gozavam do usufruto da conquista de muitos movimentos sociais de afirmação das mulheres, fossem esses feministas, decoloniais, anti-racistas, ecologistas ou de oposição política ao regime militar que tanto prejudicou o ensino e pesquisa em Filosofia de 1964 até 1980. O aspecto político opositor, por sua premência, foi muito marcado pelas professoras mais antigas e pelas mais novas em seus testemunhos. Já o relato de opressão sofrida pela condição de serem mulheres foi evidente, embora não destacado, às vezes negado, em suas falas.

Cumpre notar que na escuta daquelas que possuem assentadas na memória as teorias sobre subjetividades desenvolvidas ao longo de décadas por filósofas feministas, o desconhecimento ou a não referência a essas teorias, soou alto. Em breve consulta ao verbete sobre perspectivas feministas da subjetividade da Enciclopédia de Filosofia da Universidade de Stanford ${ }^{B}$, encontramos uma vasta bibliografia a respeito, iniciando com a obra $O$ segundo sexo de Simone de Beauvoir de 1953. Nas décadas seguintes, de 1960 aos dias de hoje, com ênfase nas décadas de 1980, 1990 e 2000, há mais de quatrocentos textos citados, entre livros e artigos de autoras, tais como: Luce Irigaray, Patricia Hilll Collins, bell hooks, Kimberlé Crenshaw, Maria Lugones, Nancy Fraser, Adriana Cavarero, Joan Scott, Judith Butler, Linda Alcoff, Marta Nussbaum, Seyla Benhabib, Sara Ruddick, Rosi Braidotti, entre muitas outras filósofas feministas que estudaram com atenção a constituição da subjetividade na filosofia, realizaram uma revisão crítica dos textos canônicos com um fôlego impressionante e inventaram uma nova forma de pensar esse esteio moderno do pensamento filosófico que é a subjetividade.

\footnotetext{
2 O G.T. de Filosofia e Gênero da Associação de Pós-Graduação em Filosofia foi fundado em 2016, sob coordenação de Susana de Castro (UFRJ).

${ }^{3}$ Cf. https:/ / plato.stanford.edu/entries/feminism-self/
} 
É da perspectiva da escuta, portanto, que olharemos para os testemunhos das professoras do departamento da USP, com base nas teorias feministas que alteraram a ideia do "eu" na filosofia, nas últimas seis décadas. Alteraram também o que podemos supor ser o autobiográfico, principalmente em relação ao modelo de autobiografia fundado na filosofia por Rousseau e Goethe, de maneira grandiosa e, sem deixar de notar, na contramão da hipérbole rousseauniana da apresentação de si, o modelo econômico e tímido da autobiografia de Hume. Com certeza as feministas aprenderam muito com Nietzsche e Benjamin ao implodirem o eu coeso e íntegro dos modelos fundantes, tornando-o múltiplo, em processo, secundário ou mesmo esvanecido. Há quem inclua Hume ao lado desses últimos, com base em sua teoria do conhecimento ${ }^{4}$, sendo que o mesmo não pode ser dito de sua escrita autobiográfica.

\section{Décadas de crítica e criação de novos parâmetros de subjetividade: o eu relacional}

Rosi Braidotti, em seu livro Pós-humanismo, lembra a importância dos movimentos feministas, anti-racistas e outros movimentos sociais, notadamente os movimentos de defesa do meio ambiente e da paz, que desde a década de 1970, teriam questionado a definição de humano. Os pontos de intersecção entre esses movimentos e teorias não eliminaram os pontos de tensão e de discussão que se tornaram intensas e mutuamente cooperativas. Ela enxerga um alvo em duas ideias motoras dessas críticas, um movimento dialético entre o eu e o outro, de um lado; e, de outro, a noção de diferença. De um lado ou de outro, o pressuposto era a de que a

subjetividade como prática discursiva e material era equiparada à consciência racional, universal e ao comportamento moral auto regulador, enquanto o Outro é definido como seu oposto negativo. Redefinida dialeticamente como "diferente de", a diferença é inscrita em uma escala hierárquica que significa inferioridade e significa "valer menos que isso". Essa violência epistêmica adquiriu conotações cruéis para pessoas da vida real que coincidiam com categorias de diferença negativa: mulheres, povos originários e outros "outros". Eles são os "Outros" sexualizados, racializados e naturalizados, cuja existência social e simbólica é descartável e desprotegida. Como sua história na Europa e em outros lugares tem sido de exclusões letais e desqualificações fatais, esses "Outros" levantam questões cruciais de poder, dominação e exclusão. (...) A geração feminista anti-humanista adotou o conceito de diferença com o objetivo explícito de fazê-lo funcionar de maneira diferente. A pergunta provocativa de Irigaray "igual a quem?” é emblemática dessa mudança da homologação ou redução para um padrão masculino de identidade 5 .

\footnotetext{
${ }^{4}$ Cf. DAMIÃO, Filosofia e autobiografia, De Jean-Jacques Rousseau a Walter Benjamin, p. 40. Da mesma autora, "O quanto de si se quer falar, o quanto de si se quer mostrar: a medida de exposição de si mesmo e suas virtudes nas narrativas autobiográficas de Rousseau e de Hume".

${ }^{5}$ Tradução nossa. BRAIDOTTI, The Posthuman, p. 24.
} 
Essa questão já era posta por Simone de Beauvoir, quando dizia: "Ele é o Sujeito, ele é o Absoluto, ela é o Outro". Ser o Outro é não ser ou ser meramente, de forma reificada, culturalmente estereotipadas ou inferiorizadas em relação aos homens. Na revisão crítica dos textos canônicos, segundo Ellen Anderson e Cynthia Willet ${ }^{6}$

as feministas argumentaram que o eu não é apenas uma questão metafísica para a filosofia, mas que também é ético, epistemológico, social e político. Respondendo a esse estado de coisas, o trabalho filosófico feminista sobre o eu assumiu três aspectos principais: (1) críticas das visões ocidentais modernas e dominantes do eu, (2) recuperações de identidades femininas e (3) reconceitualizações do eu como (a) um indivíduo relacional dinâmico, sujeito a desejos inconscientes e vínculos sociais e (b) interseccional e, mesmo, heterogêneo ${ }^{7}$.

O principal a ser notado nessas reconceitualizações feministas do eu é que esse passa a ser entendido "como um fenômeno relacional de várias camadas" . Há uma forte preocupação em evitar repetir as teorias modernas epistemológicas da subjetividade, deflagradas como "androcêntricas", "eurocêntricas", sexistas, elitistas, classistas, racistas, transfóbicas, etnocêntricas e especistas?.

A reconstituição da subjetividade é relacional porque é situada em sua história, cultura, época e local. Um eu que não é reduzido à racionalidade ou às faculdades racionais, mas que é vulnerável e posto em situação de risco e de esquecimento. Elementos desprezados, como veremos no depoimento de Marilena Chaú, como a maternidade e o que diz respeito ao mundo dos cuidados passam a ser enxergados nessa reconstituição do eu. $\mathrm{O}$ processo de educação das meninas e mulheres, já denunciado pela grande opositora de Rousseau e de Edmund Burke, Mary Wollstonecraft, em solo humanista iluminista, demonstrava que as virtudes morais não possuíam gênero e que a maneira como se ensinava as mulheres não as tornava mais virtuosas, mas as pervertia. Crítica reavivada por Beauvoir que via no processo de reificação social das mulheres sua amputação da carreira profissional e sua dependência da aprovação masculina.

$\mathrm{Na}$ noção de eu relacional encontramos a forma narrativa de si como resultado do reconhecimento circunscrito, seu ambiente sócio-cultural, provindo da experiência na qual ambições de formação de identidade possuem um contraponto: o sujeito ético e universal, cuja transparência é afirmada pela capacidade racional e via modelo masculino.

Existem diferenças e oposições nessas teorias, sendo a maior delas a que vem de correntes pós-estruturalistas que afirmam que o eu "é apenas um nó discursivo instável, e a identidade de gênero é um 'estilo corporal', a imitação e repetição de normas, frequentemente

\footnotetext{
${ }^{6}$ Autoras do verbete "Feminist Perspectives on the Self". Publicado pela primeira vez em 28 de junho de 1999 e revisado substancialmente em 19 de fevereiro de 2020.

7 Tradução nossa. ANDERSON; WILLET, "Feminist Perspectives on the Self'. Verbete da Stanford Encyclopedia of Philosophy.

8 Tradução nossa. ANDERSON; WILLET, "Feminist Perspectives on the Self". Verbete da Stanford Encyclopedia of Philosophy.

${ }^{9}$ HARAWAY, When Species Meet.
} 
exigidas por contextos culturais" ${ }^{10}$. Em outros termos, o eu é uma ilusão quando se apoia na diferença identitária de natureza biológica. Mesmo que essa autora, Judith Butler, afirme que a identidade é construída por "modos de poder", e que é preferível criar uma performance como paródia de identidades do que afirmá-las positiva ou negativamente como meio de contestação política, ela permanece no registro de relacionalidade do eu. Linda Alcofff ${ }^{11}$ ressalta a relacionalidade do eu na constituição de narrativas que explicitem as relações de formação da identidade no contexto sócio cultural.

Adriana Cavarero, em seu livro Tu che mi guardi, tu che mi racconti. Filosofia dela narrazione ${ }^{12}$, traduzido para o inglês por Relating narratives. Storytelling and Selfhood ${ }^{13}$, é uma das pensadoras que pode nos auxiliar a entender essa condição de relacionalidade. $\mathrm{O}$ tradutor para o inglês de sua obra, Paul Kottman, justifica a tradução do título original por entender, justamente, que o "eu relacional" define o eu que conta sua história, de modo diferente das narrativas do eu metafísico ou autoconstituinte da filosofia tradicional.

$\mathrm{Na}$ apresentação de seu livro, Cavarero lembra a escritora Isak Dinesen, cujo pseudônimo Karen Blixen a tornou conhecida ${ }^{14}$.

Karen Blixen conta uma história que lhe foi contada quando criança. Um homem, que vivia perto de um lago, foi acordado uma noite por um grande barulho. Saiu de noite e seguiu para o lago, mas na escuridão, subindo e descendo, indo e voltando, guiado apenas pelo barulho, tropeçou e caiu repetidamente. Por fim, ele encontrou um vazamento no dique, do qual escapava a água e os peixes. Ele começou a estancar o vazamento e só quando terminou voltou para a cama. $\mathrm{Na}$ manhã seguinte, olhando pela janela, viu com surpresa que suas pegadas haviam traçado a figura de uma cegonha no chão. Nesse momento, Karen Blixen se pergunta: 'Quando o projeto da minha vida estiver completo, verei eu ou verão outros uma cegonha?' Poderíamos acrescentar: o curso de toda vida se permite, no final, ser encarado como um desenho que tem um significado? Aparentemente, não estamos lidando com um desenho que foi previsto; não é projetado ou controlado. Pelo contrário, o pobre homem, chamado à ação por circunstâncias externas, corre e tropeça na escuridão. Ele trabalha duro e somente quando o desastre está sob controle, ele retorna para casa. Ele nunca perde de vista seu propósito, nunca abandona o objetivo de seu curso. Ao contrário, ele o conclui. Sua jornada mistura intenção com acidente. Enquanto ele é submetido a provações e tribulações, seus passos, no entanto, deixam para trás um projeto; ou, em muitos casos, um desenho resulta de sua jornada - um que tem a unidade de uma figura. O significado da história reside precisamente na unidade figurativa do desenho e neste simples 'resultado',

\footnotetext{
${ }^{10}$ BUTLER, "Gender Trouble, Feminist Theory, and Psychoanalytic Discourse".

11 ALCOFF, "Visible Identities: Race, Gender, and the Self".

12 CAVARERO, Tu che mi guardi, tu che mi racconti. Filosofia dela narraz̧ione. Seguindo uma inspirada tradução do título por Margareth de Lourdes Oliveira Nunes: Você que me olha, me conta. Filosofia da narração.

${ }^{13}$ CAVARERO, Relating narratives. Storytelling and Selfhood. Traduzindo, noutra tentativa, poderia ser: Relacionando narrativas. O contar histórias e a individualidade.

${ }^{14}$ Trata-se da passagem do livro de Karen Blixen, Out if Africa, citada nesta edição: New York, Random House, 1938, p. 201. Tradução nossa da referida passagem.
} 
que não segue nenhum plano projetado. Em outras palavras, o desenho - que não consiste apenas em marcas confusas, mas tem a unidade de uma figura não é aquele que guia o curso de uma vida desde o início. Pelo contrário, o desenho é o que é a vida, sem jamais prever ou imaginar ${ }^{15}$.

Essa história parece ser emblemática para que discussões sobre relatos autobiográficos não possam ser ingenuamente concebidos sem que a subjetividade narrativa seja refletida, bem como o registro de memória que se elabora.

A singularidade ou individualidade que marca a narrativa tem um fundamento na formulação da pergunta que fazemos, não mais “o que é o homem?”, não mais a essência de quem narra, mas "quem" narra. Uma questão que leva ao que Hannah Arendt reconhece como o que não é possível de ser exprimido externamente em termos filosóficos e que depende unicamente da pessoa que revela sua história de forma absolutamente singular. Segundo comenta Kottman:

Além disso, para Arendt, 'quem' alguém é não é absolutamente indizível, mas é revelado e manifestado através das ações, palavras e fatos dessa pessoa que, ex post facto, formam a história de vida única dessa pessoa. Arendt escreve: 'Quem alguém é ou foi, só podemos descobrir, sabendo da história por meio da qual ele próprio é o herói’ [4]. 'Quem’ alguém é, portanto, permanece inexprimível dentro da linguagem da filosofia; mas, como resultado, não permanece totalmente inefável [5]. Em vez disso, 'quem' alguém é pode ser 'conhecido' (embora isso não seja um conhecimento epistemológico) através da narração da história de vida da qual essa pessoa é protagonista ${ }^{16}$.

Cavarero recorre a Arendt para chamar a atenção para esse novo senso político da narrativa que revela quem alguém é por meio de palavras e ações, criando uma interação entre indivíduos e suas existências singulares narradas. Ao reformular a pergunta filosófica "o que é o homem?", para que da resposta seja vinculada um modelo que deve ser o paradigma do igualitário político, Cavarero adota o "quem é" para responder como se dá a singularidade do indivíduo em sua relacionalidade constitutiva com outros indivíduos. "À noção de Arendt da exposição constitutiva do eu, Cavarero adiciona, assim, a narratividade desse eu. O ‘eu narrável' - um dos elementos centrais introduzido" ${ }^{17} \mathrm{em}$ seu livro.

Quando Cavarero fala de um 'eu narrável', portanto, ela não está falando de o "sujeito" clássico ou sobre a "formação de sujeitos". O que torna uma narração um ato político não é simplesmente que essa narração invoque a luta de uma subjetividade coletiva, mas, ao contrário, que elabore e elimine a fragilidade do singular. A singularidade e unidade de um eu, que é revelado através das ações desse eu e as palavras, que depois são narradas como uma

\footnotetext{
${ }^{15}$ CAVARERO, Relating narratives. Storytelling and Selfhood, p. 4.

16 Tradução nossa. KOTTMAN, “Translator's Introduction”. In: CAVARERO, Relating narratives. Storytelling and Selfhood, pp. vii-viii.

17 Tradução nossa. KOTTMAN, “Translator's Introduction”. In: CAVARERO, Relating narratives. Storytelling and Selfhood, p. ix.
} 
história de vida única e unificada, não apresenta nenhuma das características gerais da subjetividade tradicional: interioridade, psicologia, agência, autopresença, domínio e assim por diante. Em vez disso, o 'eu narrável é um único existente', quem 'alguém ép ${ }^{18}$.

Algo a ser recomendado como discussão e que não será realizada nesse artigo, é a diferença entre Cavarero e Butler, basicamente fundada na formulação linguística e paradoxal do eu como sujeito em seus dois sentidos: de sujeito ativo ao sujeito submetido. O sujeito como sujeição ao outro é um estado possível de subjetividade para Cavarero, um momento no qual a relação com outros é de submissão, mas diferentemente de Butler, ela não afirma ser essa a condição dos indivíduos em geral, o que poderia levar alguém ao registro de invisibilidade ou de abjeção.

Por outro lado, prosseguindo na comparação que Kottman faz entre Butler e Cavarero, é muito interessante notar que na perspectiva da primeira, ainda rege a ideia de ipseidade da narrativa autobiográfica, na qual o “eu é um outro para si mesmo”. É possível nesse caso que o sujeito que conta sua história independa do outro como sendo-lhe externo e crie esse desdobramento de si mesmo, a auto-alienação dialética necessária para a formação da consciência de si e, por consequência, da narrativa de si, adotando a perspectiva da terceira pessoa sobre sua própria condição de existência.

Para Cavarero, este é o 'pretexto' envolvido na tradição da autobiografia clássica (que é paralela à genealogia do sujeito filosófico). Cavarero escreve que é 'a estranha pretensão de um eu' que se faz um outro para poder contar sua própria história... o outro é aqui o produto fantástico de uma duplicação, o complemento de uma ausência, a paródia de uma relação [34]. Em vez de repetir essa estratégia clássica, Cavarero desafia a autonomia da autobiografia filosófica ao insistir que o outro é realmente um outro $[35]^{19}$.

Por fim, é necessário que se verifique aquilo que poderia ser considerado um risco para a exposição de uma vida em sua singularidade, realizada no processo relacional de escuta: "Você que me olha, me conta". Essa exposição de si é considerada uma condição existencial que conecta o indivíduo ao social e ao político. É sempre bom lembrar que a exposição que se faz pela narrativa de uma história de vida não revela o que se é ou o que se veio a ser, mas um "quem" que se expõe na relação com outros num contexto público e político. A vulnerabilidade daquela que se expõe publicamente pode representar um choque do que sentimos ser diferente de quem pensamos ser, diante daquilo do que nos chamam. Por isso, o processo de escuta é fundamental na constituição da narrativa que expõe a si em sua singularidade galvanizada - muitas vezes petrificada como uma estátua - naquele ambiente no qual se constituiu.

\footnotetext{
18 Tradução nossa. KOTTMAN, “Translator's Introduction”. In: CAVARERO, Relating narratives. Storytelling and Selfhood, p. x.

19 Tradução nossa. KOTTMAN, “Translator's Introduction”. In: CAVARERO, Relating narratives. Storytelling and Selfhood, p. xiv.
} 


\section{A Homenagem às professoras de filosofia da Faculdade de Filosofia, Letras e Ciências Sociais (FFLCH) da Universidade de São Paulo (USP)}

Chegamos aqui, portanto, à consideração que nos importa, após caracterizar ou constituir a "escuta" das falas testemunhais ou autobiográficas que reuniu uma mesa com professoras de diferentes gerações do histórico e importante departamento de Filosofia da $\mathrm{USP}^{20}$. Algumas datas são importantes, bem como a contagem do número de mulheres que foram contratadas nos 86 anos de existência do curso de Filosofia na mais reconhecida universidade paulista e brasileira. O departamento foi fundado em 1934 no espírito do processo civilizatório, com professores franceses que ensinavam em sua língua nativa. A primeira contratação de uma professora, Gilda de Mello e Souza, veio a ocorrer apenas em 1954, 20 anos após sua fundação. De lá para cá, apenas 13 professoras foram contratadas e hoje, num corpo docente com mais de 30 professores, contam com apenas duas professoras em sua composição. Uma das quais, Silvana de Souza Ramos, que se tornou coordenadora do GT de Filosofia e Gênero da ANPOF em 2018, responsável pela organização do II Encontro do GT e por essa homenagem às professoras.

É importante marcar o suporte dado a professora Silvana Ramos pelo GT de Filosofia e Gênero. Não houve unanimidade em torno da "homenagem", por isso houve da parte da professora uma justificativa inicial bastante pertinente e afinada com os pressupostos de escuta feminista. Algumas colegas que não se dispuseram a ouvir a justificativa se retiraram antes. Por que? Por talvez não sentirem que as professoras homenageadas tivessem feito algo que ainda está em curso: a defesa do espaço acadêmico para as mulheres que estudam filosofia desde que a filosofia se tornou uma carreira oficializada, permitindo o acesso de muitos às universidades públicas e privadas. Podemos argumentar: isso é um fenômeno recente, a maioria das professoras ali reunidas já estão aposentadas e defenderam sim o espaço para mulheres num contexto permeado por agressões, mas também por afetos masculinos, não apenas violências ou discriminações. No entanto, a situação mudou muito quando o "carreirismo" tornou o cenário da filosofia mais masculino e competitivo, eliminando nos estudos as etapas de amadurecimento intelectual, o que se tornou evidente na formação de discentes nos Programas de Pós-Graduação em Filosofia no Brasil.

Carolina Araújo, professora da Instituto de Filosofia e Ciências Humanas (IFCS) da Universidade Federal do Rio de Janeiro (UFRJ) gosta de dizer que colocou um "elefante na sala" com seu artigo publicado na revista da $\mathrm{ANPOF}^{21}$, que trazia estatísticas sobre o número ínfimo de mulheres nos PPGFILs em todo Brasil. Ela percebeu o "ambiente de vestuário masculino"22, que poderia ser também alcunhado de "um ambiente de sacristia", afinal a filosofia e seus vínculos religiosos não ficaram no passado. Iniciou uma campanha para as filósofas "Quantas somos?” no Encontro da ANPOF ocorrido em 2016. Neste mesmo encontro e data, o GT de Filosofia e Gênero foi fundado e ajudou a compor a chapa vencedora que dirige essa associação desde então, sendo a vice-presidente, a fundadora do GT, Susana de Castro, desde 2018. No último encontro, realizado em 2018, ocorreu uma

\footnotetext{
${ }^{20}$ Cf. ARANTES, Um departamento francês de ultramar. Estudos sobre a formação da cultura filosófica uspiana. (Uma experiência nos anos 60). Rio de Janeiro: Paz e Terra, 1994.

${ }^{21}$ ARAÚJO, "Mulheres na Pós-Graduação em Filosofia no Brasil - 2015".

22 PODCAST do PPGLM, Série: Quantas Filósofas? "Carmel Ramos entrevista Carolina Araújo".
} 
primeira homenagem às filósofas e outra campanha, de cunho político afirmativo, com distribuição de adesivos: \#elasSim, \#eleNão. Na homenagem, inicialmente pensada para algumas professoras reconhecidas, todas as professoras e estudantes presentes foram convidadas a subir ao palco e todas foram simbolicamente homenageadas.

Podemos dizer que essa foi uma primeira ressignificação da palavra "homenagem" que passou por outro processo semelhante nas palavras da organizadora do evento na USP:

Se homenagem é um substantivo feminino, isso é uma homenagem.

Se homenagem é um juramento de fidelidade, de subordinação, de respeito do vassalo ao senhor, isso não é uma homenagem.

Se homenagem é um ato público, como mostra de admiração e respeito por alguém, isto é uma homenagem.

A mesa é e não é uma homenagem, há ambiguidade e ironia, porque é uma provocação colocar essas mulheres aqui, uma afirmação nossa e é um jeito de contar nossa história - uma contação de história.

Contar a história de um ponto de vista que nunca antes tenha sido contado, nesse ambiente público e acadêmico, no qual vidas singulares foram constituídas ao longo de muitos anos, pode ser um exercício de exposição perigoso, mas de imensa importância para a memória e atualização desta num contexto político que parece ter colocado a todas na contramão do que poderia ser a formação e a atuação em filosofia no Brasil. Um momento de perigo que contrasta com a expansão de uma manifestação múltipla e potente que emergiu há apenas 4 anos no contexto nacional da formação e ensino de Filosofia. Nem todas se dizem feministas, preferem falar em gênero, em mulherismo, há conflitos e discordâncias, mas essas frentes de mulheres se constituíram como uma força comum e atuante ${ }^{23}$. Poupemo-nos da descrição de detalhes e da transcrição das falas, pois tudo isso está disponível e acessível na plataforma do YouTube ${ }^{24}$. Vamos a alguns aspectos das apresentações que dizem respeito ao trabalho de escuta, como suas falas repercutiram para a autora singular que escreve este artigo, esperando que outras, na leitura, possam se reunir à constituição pública das falas e das escutas que estão intrinsecamente relacionadas, cada qual em sua autenticidade e individualidade.

$\mathrm{Na}$ abertura da mesa foi apresentado um vídeo sobre a primeira professora do departamento, Gilda de Mello e Souza, comentado posteriormente pelas participantes que a conheceram. Registros documentais que mostram seu parentesco com Mário de Andrade, sua formação e imagens documentais. Destacam-se nas menções, sua condição de professora de Estética, algo tão desvalorizado que a fez manter sua tese de doutorado trancada durante

\footnotetext{
${ }^{23}$ É possível listar a quantidade de pesquisas, publicações de artigos, livros organizados ou autorais, teses, dissertações, trabalhos de conclusão de curso, pesquisas de iniciação científica realizadas nos últimos anos, tarefa que certamente os websites que vem se organizando com muitas atividades (oferta de minicursos, palestras, publicação de artigos, blogs, podcasts, vídeos, entrevistas), como a Rede Brasileira de Mulheres Filósofas outra iniciativa de Carolina Araújo (https://www.filosofas.org/), o recém fundado Instituto As Pensadoras, sob iniciativa de Rita de Cássia Fraga Machado, e a Red de Mujeres Filósofas de América Latina (https://www.reddem.org/pt/). Pelo lado das ações militantes, muitos coletivos foram formados, projetos de extensão em ponte entre Universidade e comunidades sociais.

24 MESA: Homenagem às professoras do Departamento de Filosofia da USP. Acessível: https://www.youtube.com/watch?v=15ZG7FXlkWY. Em 15/05/2020.
} 
décadas antes de publicá-la, cujo assunto era a moda; e sua heroica tarefa na gestão do departamento durante os anos duros da ditadura militar.

O depoimento de Tessa Moura Lacerda foi particularmente comovente e aberto por reunir questões políticas familiares trágicas, também vinculadas ao período da ditadura militar, seguido de um grande elogio à memória de sua formação como aluna das professoras homenageadas. Sobre sua condição atual de professora no departamento, sobre conflitos que possa enfrentar, pouco disse. Acrescentou que a necessidade de estudar as teorias feministas que reúnem a questão de gênero, classe e raça, veio da demanda das alunas, com as quais formou um grupo de estudos para leitura de textos.

A professora Maria das Graças de Souza fez uma apresentação na qual pouco disse de si, mostrando consonância na discussão dos temas que foram tematizados no encontro e com eles dialogou de maneira sucinta e clara. Falou no plural: "Falarei de nossa trajetória de mulheres a partir do que ouvi nos três dias do evento". De maneira mais próxima às teorias sobre subjetividade, a professora focou no processo de formação de identidades, alertando para o "reducionismo" que esse processo significa. Para explicá-lo, convocou Edward Said, Achille Mbembe, Grada Kilomba e Laura Esquivel, acreditando que há uma observação comum nas teorias desses autores que alerta para o fato de que "a atribuição de identidades se faz com a inferiorização daqueles que são identificados”. Essa atribuição é feita pelo colonizador branco ocidental que passa a nomear o que é o oriental, o negro, os povos originários e, pela nomeação, submete a todos. O mesmo processo ocorreria com as mulheres. O que o caracteriza é a "designação geral que esconde diferenças". Neste ponto, poderíamos retornar aos pressupostos iniciais deste artigo e encontrar muita consonância com as teorias lá indicadas, por exemplo, por Rosi Braidotti. A professora lembra duas figuras de mulher: a escrava Anastácia e sua mordaça e a índia mexicana Malinche que seria uma interlocutora entre seu povo e Cortez, como uma esperança de "fazer valer a palavra e não as armas". No nosso processo de colonização, essas histórias são repetidas, como da "índia Paraguaçu" (povo Tupinambá) e a "índia Vanuíre" (povo Kaingang), interlocutorasprisioneiras ou "heroínas" capturadas. A positividade da fala das mulheres foi reunida à multiplicidade do que somos: multidão falantes, legião de mulheres falantes. Arendt e Butler são convocadas ao final para qualificar a ação dessa legião: "como ação concertada (Arendt) que responde às urgências de nosso tempo (Butler)". Não houve um testemunho ou críticas ou um posicionamento como professora do departamento, mas consonância e diálogo com a legião de mulheres que nos três dias de encontro apresentaram diferentes perspectivas e teorias que tinham a si próprias como tema.

A professora Scartlett Zerbetto Marton lançou a tarefa de apresentar uma autobiografia intelectual, como se esta fosse uma convenção e não um problema. Fez referência à prova do concurso que prestou para se tornar professora e que exigia a apresentação de um currículo comentado. Lembrou do título e de sua publicação em 2004: "A irrecusável busca de sentido". Forneceu datas e fatos de suas etapas na vida acadêmica sempre pontuados com algumas frases que se repetiam em sua narrativa: "Muito bem, a mulher, a professora que sou...". Particularmente essa frase pontuava enfrentamentos diante de situações de discriminação dessa condição ou, como disse, "mácula de nascença", qual seja, a de ter nascido mulher. Como sinais de resistência, a professora nomeou muitas de suas atividades acadêmicas como o Grupo de Estudos Nietzsche e os Cadernos Nietzsche, bem como o processo de internacionalização do qual participa levando o nome do departamento 
da USP mundo afora. Encerrou com o que talvez tenha melhor caracterizado sua narrativa de resistência: "compreender a necessidade de enfrentar obstáculos, venham de onde vier. Ser combativa e resistir na universidade e no país".

Olgária Chain Feres de Matos fez uma sucinta exposição dos laços acadêmicos com Marilena Chauí, Gilda de Melo e Souza e Maria Sílvia (ausente, mas nomeada no evento), com quem teria feito um curso sobre o amor. Cita o método uspiano de leitura e compara a distinção benjaminiana entre o comentarista e o crítico. Quanto ao tema, relativiza-o um pouco. Concorda que os filósofos não "têm muito apreço pelas mulheres", mas cita Sócrates como um exemplo de apropriação positiva do trabalho de parteira da mãe e quando se refere ao amor, cede a palavra a uma mulher, Diotima. Claro que, sabendo um pouco sobre essa personagem de Platão, é possível considerar que a ironia ou o ardil platônico-socrático diante de poetas tão importantes, poderia ser a explicação de se submeter a uma mulher mais velha, quando ainda jovem, em questões que a ele já não mais importavam. Para ela a filosofia é andrógina, as falas são intercambiantes e ela, particularmente, apesar de percalços, sentiu-se bem acolhida no departamento onde foi professora. De todas as narrativas, talvez a sua tenha sido a mais recolhida.

A professora Maria Lúcia Mello e Oliveira Cacciola, igualmente, diz ter se sentido "em casa" no departamento de Filosofa e que a relação com os colegas foi gratificante. Disse desconhecer o tema gênero, mas ter "simpatia e preocupações". Elogiou colegas como Marilena Chauí e Paulo Arantes. Com inegável bom humor, perguntou a Otília, esposa de Paulo Arantes, se poderia "falar de homem ali". Em seguida, forneceu uma saborosa narrativa sobre seu convívio com três amigas artistas, todas reconhecidas: Hilda Hilst, Mira Schendel e Amélia Toledo. A primeira, escritora, as outras, artistas plásticas. Por meio do trabalho artístico delas descobriu as opressões, as curtições e observou que essas mulheres "faziam de suas moradas lugar de invenção, de determinação do improvável, do jogo e do fino humor".

A professora Andréa Altino de Campos Loparic afirmou que não havia preparado nada, que pensava ali no momento e "pegava uma carona" no que já havia sido dito pelas colegas. Afirmou algo que Marilena Chauí viria a repetir, de que nunca pensou na condição de ser feminista por vir de um matriarcado, uma família de mulheres fortes. Academicamente disse não ter sofrido discriminação, talvez por ter sido professora de lógica. Mas, sentiu-se discriminada na fala, por ter sotaque de nordestina. "Nordestino não diz que é discriminado porque tem vergonha. O sotaque é como a cor da pele, não dá para esconder”. Contou sobre sua militância política de esquerda, já mencionada pela professora Tessa Moura, seu período na Europa e que só após se aposentar passou a dizer o que pensa.

A professora Otília Beatriz Fiori Arantes abriu sua fala com muita franqueza, dizendo o oposto de algumas outras falas: "Vou dizer algo deselegante: nunca me senti identificada com o departamento, sempre me senti marginal". Não se sentiu discriminada como pessoa, mas como professora de Estética, que era vista pelos colegas homens como uma disciplina "fútil, sem importância". Isso se dava, a seu ver, porque os professores franceses restringiam a filosofia "à história da filosofia e à epistemologia - o resto era futilidade". Retirou a professora Gilda do pedestal, no qual eventualmente a colocam, para dizer que "na época [a professora Gilda] foi massacrada e sofria muito". Comenta como foi atacada pelo professor João Cruz Costa que a fez desistir de dar seu curso e veio a publicar sua tese sobre moda trinta e sete anos depois de a ter defendido. Em seu testemunho, havia "preconceito contra 
a Estética e contra mulher". De sua experiência que a fez deslocar-se para a faculdade de Arquitetura (FAU), ela salva as relações com Marilena Chauí, Bento Prado Jr., quem julgava ser muito especial. Fala com entusiasmo dos seminários que organizou com alunos e de ter introduzido a discussão sobre a produção de arte contemporânea e o pós-modernismo na Arte em Revista ${ }^{25}$, publicação que marcou os estudos na área. Segundo diz, no departamento "ou os professores davam os textos clássicos de Estética ou não eram considerados".

Por fim, a professora Marilena Chauí, foi quem, sem sombra de dúvida, manteve uma forte conexão com as colegas que a citam, tendo sido a segunda contratada no departamento após a contratação de "Dona Gilda", carinhosamente assim nomeada. Sua narrativa foi igualmente franca e autobiográfica, regada por muita ironia. Como a professora Andrea Loparick, disse que sua família tinha mulheres muitos fortes e que não se sentia ameaçada. Contou como passou da condição de pertencer à "nata do ensino paulistano" para se tornar uma "violetinha" no primeiro dia de aula do curso de Filosofia, na antiga Unidade na rua Maria Antonia. "O que as violetinhas vieram fazer aqui? Marido é nas Letras". Uma primeira ironia vinda daquele que mais tarde foi seu colega, o professor Arthur Gianotti ${ }^{26}$. Para ela, esse tipo de tratamento foi uma constante no departamento, com ressalvas: Bento Prado Jr., Gérard Lebrun e Michel Debrun. Como a professora Otília Arantes, Marilena Chauí não camuflou os problemas ou pensou que esses deveriam ser respondidos com indiferença. Indicou certos sinais que permanecem de alguma forma no meio acadêmico, cuja origem ocorreu no processo de seleção para se tornar monitora na pós-graduação: a escolha se baseava numa exigência, não em uma escolha entre pessoas, estudantes ou profissionais, mas entre "gênios". Ou seja, os alunos não disputavam uma vaga de monitoria, mas a "genialidade". Cruz Costa se opunha a contratação de mulheres e foi na festa de sua aposentadoria que teria se dirigido à grávida Marilena e dito: "Ô Dona Marilena, a senhora é muito bonita, muito inteligente, mas com essa barriguinha não vai dar". Disse isso com uma batidinha em sua barriga. A essa cena grotesca foi acrescentada uma muito pior na reunião que definiria quem assumiria o cargo de professor no departamento: "mas ela pode ser contratada e podemos perguntar a ela se ela topa se esterilizar". Foi nesse ponto que um colega convidou o já referido professor a levar um soco na cara do lado de fora da faculdade. E, segundo sua narrativa, foi por causa dessa reação que seu nome teria sido aprovado. Ela

\footnotetext{
25 “Arte em Revista é uma revista cultural, publicada no período de 1979 a 1984 pelo Centro de Arte Contemporânea - CEAC, São Paulo, sob a coordenação de Otília Beatriz Fiori Arantes, Celso Fernando Favaretto e Matinas Suzuki Júnior. Essa revista foi editada até o número sete pela Editora Kairós em São Paulo, e o oitavo número foi publicado pelo CEAC e editado com a colaboração parcial da FAPESP. Trata-se de uma revista monográfica, que dedica cada número a uma determinada temática. Os números um e dois tratam da efervescência cultural dos anos 60 e o número três é dedicado à questão do popular no Brasil. O número quatro tem como temática a arquitetura nova. Os números cinco e oito tratam da mesma temática: independentes. O número seis enfoca o teatro e o número sete destaca a questão do pós-moderno" (NIEDZIELUK, "Uma apresentação de Arte em Revista”).

${ }^{26}$ José Arthur Giannotti deu uma entrevista à revista Época em fevereiro de 2020, quase aos 90 anos. O título "José Arthur Giannotti, entre bordados e insultos" repercute bem a referência a ele nesse testemunho de Chauí e repete suas próprias palavras: "Se você for ao Departamento de Filosofia da USP, vai encontrar várias bordadeiras, gente que pega um pedaço de Descartes e estuda, estuda, estuda aquele negócio e fica lá bordando. São estudos interessantes, mas são bordados", reclamou. "Quando saem do bordado, alguns fazem uma mistureba como a que faz o Olavo de Carvalho ou outros críticos do chamado 'marxismo cultural'. Eles estudam um autor e insultam os outros. Nos últimos tempos, o que temos na filosofia são dois abismos: bordados e insultos". Em sua defesa, poderão dizer que ele não faz insultos, mas ironia, em relação aos quais uns/umas riem, outros/outras não. Disponível em: https://epoca.globo.com/brasil/jose-arthur-giannottientre-bordados-insultos-24262688
} 
diz ser testemunha também do "tratamento medonho" recebido pela D. Gilda. Uma narrativa potente, dando nome aos bois e aos abusos, mas que não the pareciam assim na época. Julgava-os "grosseria". Disse: "Em certos casos é difícil perceber a discriminação e eu não percebi". Contou ainda dos anos de repressão política, do exílio dos colegas, de como o Tratado teológico-politico de Spinoza a ajudou a entender a situação política e, como professora, a "vacinar as cabeças jovens contra o que está acontecendo" neste momento. Conclui negativamente: "Minha sensação é de que minha vida, a dedicação no departamento, é que minha vida foi em vão".

Ao finalizar com essa frase que soou tão melancólica, ouvimos a contestação vinda da professora Andrea Loparick que puxou um coro: \#eleNão...\#ElasSim, para lembrar a campanha do GT de Filosofia e Gênero no último encontro da ANPOF contra - é preciso lembrar - a eleição presidencial e o candidato que se tornou vitorioso e trouxe à tona um patriarcalismo roto e violento contra tantas mulheres. Algo que nos leva ao movimento de refluxo da imagem da onda e da atitude política caracterizada pela resistência.

\section{Conclusão}

As narrativas ou a contação de histórias, de acordo com a provocação da organizadora do evento, Silvana Ramos, foram muito importantes para quem as assistia e as escutava. O desenho das vidas, mais ou menos expostas, mostra uma existência coletiva marcada por autoritarismos políticos, interna ou externamente à vida acadêmica. É muito importante lembrar que, do surgimento do departamento de Filosofia há 86 anos, 21 um deles foram vividos sob o regime da ditadura militar. Um regime que eliminou do currículo das escolas a disciplina da Filosofia. Travou-se uma luta, a partir da década de 1980 para reimplantar a disciplina nos currículos. Vivíamos um momento no qual uma disciplina pequena voltada para estudos de gênero, de questões étnicas e raciais adentrava nos currículos dos cursos de graduação em Filosofia. É de se entender o "tudo isso foi em vão" de Chauí. Foi uma construção de base implantada nos colégios, nos cursos de graduação e a própria construção de uma associação nacional de pós-graduação, a ANPOF, que inseriu na discussão esses temas vistos como alheios ao universo acadêmico da Filosofia, quais sejam: questões de gênero, os feminismos, o decolonialismo, as questões étnicas e raciais. Todas essas questões estão interseccionadas e tocam diretamente o mundo real em que vivemos, fortemente associadas às questões emergenciais do meio ambiente com o registro da pandemia no início de 2020 e da invasão desenfreada de territórios indígenas e da floresta amazônica. Como não refletir sobre essas questões emergenciais? Como permanecer nos departamentos severamente organizados por poderes descaradamente patriarcais e pensar que estamos "fazendo filosofia"?

Essas não são questões retóricas, são problemas que vivenciamos, pois os departamentos não são ilhas à parte do contexto político e ambiental em que vivemos. As histórias dessas professoras no departamento de Filosofia da universidade mais reconhecida do Brasil, sem preterir o que se estuda e se desenvolve nas outras, mas particularmente, o departamento de Filosofia tem uma história a contar que coincide com o que experimentamos hoje, talvez, de maneira mais brutal ainda, pois sob as vestes de um estado democrático e não de uma ditadura promulgada. 
Importar Adriana Cavarero para avaliar como os testemunhos nos auxiliam a perceber as individualidades em contexto, a exposição política de narrativas que demandam uma escuta e nesta conjuntamente se realiza, para compor uma subjetividade relacional das mulheres, significa qualificar as falas que passam pelo tormento constante da desqualificação. Uma desqualificação que não separa o pessoal do profissional, pois que age para oprimir a diferença, seja ela de gênero, de raça e de classe social.

A homenagem às professoras do Departamento de Filosofia da USP promoveu um encontro afetivo e significativo no que diz respeito a muitas questões. Uma que permanece em aberto diz respeito à necessidade de engajamento das professoras e das alunas, um engajamento político e reflexivo, de forma a reunir vida, obra e profissão na constituição de um eu que se constitui na relacionalidade.

\section{Referências bibliográficas}

ALCOFF, Linda Martin. "Visible Identities: Race, Gender, and the Self". In: Studies in Feminist Philosophy. New York: Oxford University Press, 2006.

ANDERSON, Ellen; WILLET, Cynthia. "Feminist Perspectives on the Self'. Verbete da Stanford Encyclopedia of Philosophy. Publicado pela primeira vez em 28 de junho de 1999 e revisado substancialmente em 19 de fevereiro de 2020. Acessível em: https://plato.stanford.edu/entries/feminism-self/. Acesso em 05/05/2020.

ARANTES, Paulo. Um departamento francês de ultramar. Estudos sobre a formação da cultura filosófica uspiana. (Uma experiência nos anos 60). Rio de Janeiro: Paz e Terra, 1994.

ARAÚJO, Carolina. "Mulheres na Pós-Graduação em Filosofia no Brasil - 2015”. São Paulo: ANPOF, $2016 . \quad$ Disponível em http://anpof.org/portal/images/Documentos/ARAUJOCarolina Artigo 2016.pdf.

Acesso em: 15/05/2020.

BEAUVOIR, Simone. O Segundo Sexo. 2 vols. Tradução de Sérgio Milliet. São Paulo: Difusão Europeia do Livro, 1970.

BRAIDOTTI, Rosi. The Posthuman. Malden: Polity Press, 2013.

BUTLER, Judith. "Gender Trouble, Feminist Theory, and Psychoanalytic Discourse". In: Feminism/Postmodernism. Linda J. Nicholson (Org.). New York: Routledge, 1990.

CAVARERO, Adriana. Relating narratives. Storytelling and Selfhood. Tradução e introdução de Paul A. Kottman. Londres: Routledge, 2000.

DAMIÃO, Carla M. Filosofia e autobiografia. De Jean-Jacques Roussean a Walter Benjamin. São Paulo: Loyola, 2006.

"O quanto de si se quer falar, o quanto de si se quer mostrar: a medida de exposição de si mesmo e suas virtudes nas narrativas autobiográficas de Rousseau e de Hume". In: 
OUBIÑA, O.P.; PAULA, M. G. e VIDAL, D. P. (orgs.). Heterodoxias. Filosofia e literatura. Braga: Edições Humus, 2021.

HARAWAY, Donna. When Species Meet. Minneapolis: University of Minnesota Press, 2008.

"A manifesto for cyborgs: Science, technology, and socialist feminism in the 1980s". In: Socialist Review, 5 (2), 1985, pp. 65-107.

. "Situated knowledges. The science question in feminism as a site of discourse on the privilege of partial perspective”. In: Feminist Studies, 14 (3), 1988, pp. 575-99.

Simians, Cyborgs and Women. London: Free Association Press, 1990.

hooks, bell. Ain't I a Woman. Boston: South End Press, 1981.

IRIGARAY, Luce. Speculum of the Other Woman. Ithaca/Nova Iorque: Cornell University Press, 1985.

MBEMBE, Achille. “Necropolitics”. In: Public Culture, 15 (1), 2003, pp. 11-40.

NIEDZIELUK, Luzinete Carpin. "Uma apresentação de Arte em Revista”. In: Boletim de Pesquisa NELIC, vol. 1, n. 1 - Periodismo contemporâneo em perspectiva (1997).

PODCAST do PPGLM. Série: Quantas Filósofas? "Carmel Ramos entrevista Carolina Araújo". 26/05/2020. Acessível em: https://www.filosofas.org/post/podcastppglm

SAID, Edward. Orientalism. Harmondsworth: Penguin Books, 1978.

SANTOS, Magda Guadalupe. "O feminismo e suas ondas”. In: Revista Cult, 5 de setembro de 2017. 